\title{
Association of glutathione-S-transferase polymorphisms with atopic dermatitis risk in preschool age children
}

\author{
Jayong Chung*, Se-Young Oh and You-Kyung \\ Shin \\ Department of Food and Nutrition and Research \\ Institute of Science for Human Life, College of \\ Human Ecology, Kyung Hee University, Seoul, Korea
}

\begin{abstract}
Background: Glutathione S-transferase (GST) enzymes are critical for detoxifying reactive oxygen species (ROS) and their products which have been implicated in the pathology of inflammatory diseases such as atopic dermatitis (AD).

Methods: We investigated the effects of genetic polymorphisms of GST on the risk of AD in preschool age children. Biomarkers for oxidative stress were also evaluated with respect to GST genotype.

Results: The GSTP1 Val105 allele was significantly associated with an increased risk of $A D$ [odds ratio $(O R)=1.62, p<0.05]$. The combination of the GSTP1 Val105 allele and the GSTT1 null genotype further increased this risk by 2.3 -fold $(p<0.01)$. No association was observed for the GSTM1 null or GSTT1 null genotype alone. In children with $A D$, blood total antioxidant capacity was significantly less $(p<0.001)$, while malondialdehyde was higher $(p=0.12)$. Children with the GSTP1 Val105 allele had significantly lower concentrations of erythrocyte glutathione compared to GSTP1 Ile/lle homozygotes ( $p=0.03$ ).

Conclusions: Our study suggests that the GSTP1 Val105 allele is an important determinant of susceptibility to $A D$ in preschool age children and increased oxidative stress may play a role in the pathogenesis of AD.

Clin Chem Lab Med 2009;47:1475-81.
\end{abstract}

Keywords: atopic dermatitis; glutathione-S-transferase; oxidative stress; polymorphism; preschool age children.

\section{Introduction}

Atopic dermatitis (AD) is a chronic inflammatory skin disease characterized by pruritic and eczematous skin lesions in distinct locations. The onset of $A D$ usually occurs in early childhood, with $\sim 80 \%$ of cases having

\footnotetext{
*Corresponding author: Jayong Chung, PhD, Department of Food and Nutrition Kyung Hee University, Hoegi-dong 1, Dongdaemun-gu, Seoul 130-701, Korea

Phone: +82-2-961-0977, fax: +82-2-968-0260,

E-mail: jchung@khu.ac.kr

Received April 5, 2009; accepted August 5, 2009;

previously published online October 21, 2009
}

clinical symptoms by 5 years of age (1). AD is the most common allergic childhood disease, affecting up to $20 \%$ of children worldwide (2).

While the pathology of $A D$ is very complex and not fully understood, it is widely accepted that both genetic and environmental factors contribute to the development of AD. The genetic contribution seems to be particularly strong; results from twin studies show that disease concordance rates are much higher in monozygotic $(72 \%-86 \%)$ compared with dizygotic twins (21\%-23\%) (3). In addition, recent studies have found significant associations between $A D$ and polymorphisms in genes such as IL4,IL13,IL4R, CMA1, and SPINK5 (4). These data suggest that multiple genetic factors contribute to the development of AD.

Inflammation is a critical feature of $A D$ and is often associated with increased production of reactive oxygen species (ROS). These can cause oxidative damage to cellular components such as DNA, lipids and proteins. In skin inflammation associated with $A D$, ROS are released during the activation and infiltration of lymphocytes, monocytes, and eosinophils (5-7). In addition, markers of oxidative stress have been shown to be increased in children with $A D(8)$, implicating ROS and their products in the pathology of $A D$. Thus, it is possible that genetic factors that affect the capacity of cells to detoxify ROS and their products are important determinants in the development of AD.

Glutathione S-transferases (GSTs) belong to a multigene family of phase II detoxification enzymes and protect cells against oxidative damage. GST detoxifies ROS and their products by catalyzing conjugation with reduced glutathione (GSH) prior to excretion from the body (9). Several genetic polymorphisms have been identified in GSTP1, GSTM1, and GSTT1 isozymes. A single nucleotide substitution (A-G), resulting in an Ile to $\mathrm{Val}$ change at residue 105, has been associated with altered heat stability and substrate preference of GSTP1 (10). Similarly, homozygous deletion of the GSTM1 and GSTT1 genes leads to the absence of the GSTM1 and GSTT1 proteins and their activity resulting in a null phenotype (11). Previous studies have reported an association between GST polymorphisms and an increased risk of inflammatory diseases such as asthma (12-16) and rheumatoid arthritis (17). A limited number of studies have examined the association of GST polymorphisms with risk of $A D$; the findings have been inconclusive (18-20). The purpose of this study was to investigate the relationship of polymorphisms in GSTM1, GSTT1, and GSTP1 with the risk of AD in preschool age children. In addition, biomarkers of oxidative stress were 
analyzed with respect to GST polymorphisms in children with $A D$ and healthy children.

\section{Materials and methods}

\section{Subjects}

To investigate the association between various selected factors and childhood AD, we conducted a cross-sectional, population-based study using a convenience sample of children, 2-6 years old, from 18 preschools located in two metropolitan cities (Seoul and Incheon) of Korea. Of the 1571 children who participated in the cross-sectional study, 765 were recruited for the genetic case-control study. Of these, we selected $A D$ cases and controls based on responses to questions in the Korean version of the International Study of Asthma and Allergies in Childhood (ISAAC) questionnaire (21). AD was considered to be present if the children's parents replied positively to the following questions: "Has your child ever had an itchy rash (also called atopic dermatitis), which was coming and going for at least 6 months?" and, "Has your child had this itchy rash at any time in the last 12 months?". The children whose parents provided negative responses to both questions and who had not taken any medication due to $A D$ were assigned as control subjects. All of the study subjects were Korean. Information concerning basic demography and history of family atopic diseases was also collected from the questionnaire. The severity of $A D$ was evaluated by a pediatrician using the Scoring Atopic Dermatitis (SCORAD) index. All participants provided written informed consent for study participation. The study protocol was approved by the Ethics Committee of the College of Human Ecology at Kyung Hee University.

\section{Genotyping}

Genomic DNA was extracted from buffy coats using the AxyPrep $^{\mathrm{TM}}$ Blood Genomic DNA miniprep kit (Axygen biosciences, Union City, CA, USA). Polymorphism in GSTP1 Ile $105 \mathrm{Val}$ was identified using the PCR-restriction fragment length polymorphism (RFLP) method, as described previously (22). Briefly, $50 \mathrm{ng}$ genomic of DNA was used as template in a PCR reaction with the HotStar ${ }^{T M}$ DNA polymerase kit (Qiagen, Valencia, CA, USA) and an MJ mini gradient thermal cycler (Bio-Rad, Hercules, CA, USA). PCR conditions were initial denaturation at $95^{\circ} \mathrm{C}$ for $5 \mathrm{~min}$, followed by 35 cycles of $55^{\circ} \mathrm{C}$ for $30 \mathrm{~s}, 72^{\circ} \mathrm{C}$ for $30 \mathrm{~s}$, and $95^{\circ} \mathrm{C}$ for $30 \mathrm{~s}$, and a final extension at $72^{\circ} \mathrm{C}$ for $5 \mathrm{~min}$. PCR products (176 bp) were digested with 2.5 units A/w26I (New England Biolabs, Ipswich, MA, USA), separated on a $3.5 \%$ agarose gel and stained with ethidium bromide. Bands were detected using the Gel Doc XR system (Bio-Rad, USA). The presence of the GSTP1 Val105 allele was identified by detection of cleaved PCR products (91 bp and $85 \mathrm{bp}$ ) following digestion. A multiplex PCR method was used to detect GSTT1 and GSTM1 polymorphisms, with the $\beta$-globin gene used as internal standard. Briefly, GSTM1, GSTT1, and $\beta$-globin genes were amplified simultaneously amplified by PCR using mixed primers for each gene, as described by Wilson et al. (23). PCR conditions were initial denaturation at $94^{\circ} \mathrm{C}$ for $3 \mathrm{~min}$, followed by 27 cycles of $94^{\circ} \mathrm{C}$ for $30 \mathrm{~s}, 62^{\circ} \mathrm{C}$ for $30 \mathrm{~s}$, and $72^{\circ} \mathrm{C}$ for $45 \mathrm{~s}$, and a final extension step of $10 \mathrm{~min}$ at $72^{\circ} \mathrm{C}$. Following amplification, the PCR products were analyzed on a $2 \%$ agarose gel and stained with ethidium bromide. The presence or absence of the GSTT1 (480 bp) and GSTM1 (215 bp) genes was determined in the presence of the control $\beta$-globin gene (268 bp).

\section{Serum total antioxidant capacity (TAC)}

Serum TAC was measured using a commercially available kit (Antioxidant Assay kit, Cayman chemical, Ann Arbor, MI, USA) following the manufacturer's instructions. The assay is based on the ability of antioxidants to inhibit the oxidation of ABTS [2,2'-Azino-di-(3-ethylbenzthiazoline sulfonate)] to $\mathrm{ABTS}^{+}$by metmyoglobin (24). The amount of $\mathrm{ABTS}^{+}$produced was monitored spectrophotometrically at $750 \mathrm{~nm}$. TAC of serum was compared with that of Trolox, a watersoluble tocopherol analogue, and quantified as the $\mathrm{mM}$ Trolox equivalent.

\section{Erythrocyte total GSH}

Erythrocyte total GSH concentrations were determined as described by Rahman et al. (25). Briefly, erythrocyte pellets were resuspended in four volumes $5 \%$ meta-phosphoric acid (MPA) to prevent oxidation of GSH. Following centrifugation at $3000 \times g$ at $4^{\circ} \mathrm{C}$ for $10 \mathrm{~min}$, the clear supernatants were collected and mixed with Ellman's reagent [DTNB (5,5'dithio-bis(2-nitrobenzoic acid))] and GSH reductase in the dark. After incubation at room temperature for $30 \mathrm{~s}$, the reactions were initiated by the addition of $\beta$-NADPH. The rate of formation of TNB at $412 \mathrm{~nm}$ during the first $2 \mathrm{~min}$ was proportional to total GSH concentration. Values for total GSH were calculated from a standard curve and expressed as $\mu \mathrm{mol} / \mathrm{g} \mathrm{Hb}$.

\section{Plasma malondialdehyde (MDA)}

Plasma MDA was measured using a commercially available kit (Bioxytech ${ }^{\circledR}$ MDA-586 ${ }^{\mathrm{TM}}$, Oxis International, Inc, Foster City, CA, USA). This colorimetric assay uses N-methyl-2-phenylindole (NMPI) as chromogen. It reacts specifically with MDA, but not with other lipid peroxidation products such as 4-hydroxyalkenals. Plasma MDA concentrations were derived by calculating the third derivative spectrum of the absorption spectrum $(400-700 \mathrm{~nm})$ for each sample, according to the manufacturer's recommendations. Third derivative spectroscopy helps eliminate or reduce the effects of baseline drift and interference from other biologic compounds in the sample.

\section{Statistical analyses}

All data were analyzed using SAS for Windows 9.1 (SAS Institute Inc., Cary, NC, USA) and SigmaPlot 10.0 (Systat Software Inc., San Jose, CA, USA). To test differences between children with $A D$ and healthy controls, Student's ttest or the $\chi^{2}$-test was used, as appropriate. For the association between GST genotypes and risk of $A D$, logistic regression analysis was performed to calculate the odds ratio $(\mathrm{OR})$ and $95 \%$ confidence intervals $(\mathrm{Cl})$, after controlling for gender and age.

\section{Results}

Associations between GST polymorphisms and AD susceptibility were studied in 124 unrelated children with AD and 260 healthy children. Table 1 summarizes the characteristics of study participants. Compared to controls, the group with AD had significantly higher concentrations of serum total IgE and blood eosinophil counts, typical characteristics of AD. In addition, the proportion of children with a parental history of allergic diseases was significantly higher among children with $A D$ compared with controls. Age, body 
Table 1 Characteristics of the study population ${ }^{\mathrm{a}}$.

\begin{tabular}{|c|c|c|c|}
\hline Characteristics & $\begin{array}{l}A D^{b} \text { patients } \\
(n=124)\end{array}$ & $\begin{array}{l}\text { Controls } \\
(n=260)\end{array}$ & $p-$ Value $^{\mathrm{c}}$ \\
\hline Age, years & $5.3 \pm 1.8$ & $5.2 \pm 1.5$ & 0.58 \\
\hline Boy, \% & 54.0 & 49.2 & 0.38 \\
\hline $\mathrm{BMI}, \mathrm{kg} / \mathrm{m}^{2}$ & $15.6 \pm 1.6$ & $15.3 \pm 1.7$ & 0.19 \\
\hline Total IgE, U/mL & $395.7 \pm 737.0$ & $205.0 \pm 341.0$ & 0.01 \\
\hline Eosinophil count, / $\mu \mathrm{L}$ & $342.2 \pm 210.8$ & $290.3 \pm 190.4$ & 0.02 \\
\hline \multicolumn{4}{|c|}{$\begin{array}{l}\text { Parental history of allergic } \\
\text { diseases }^{d}, \%\end{array}$} \\
\hline Both parents & 17.7 & 11.2 & \\
\hline Father or mother & 31.5 & 25.0 & 0.04 \\
\hline None & 50.8 & 63.8 & \\
\hline
\end{tabular}

aalues are mean $\pm S D$ or $\%$; ${ }^{b} A D$, atopic dermatitis. ${ }^{c}$ differences between AD patients and controls were tested by $\chi^{2}$ or Student t-test; dallergic rhinitis, asthma or atopic dermatitis.

mass index (BMI), and the proportion of males were not different between the two groups. The severity of $A D$ as evaluated by the SCORAD index showed that most children with $A D(80 \%)$ in the study suffered from mild disease (data not shown).

Table 2 summarizes the distribution of GSTM1, GSTT1, and GSTP1 genotypes among children with $A D$ and controls. In children with $A D$, the frequencies of GSTM1 null and GSTT1 null were $58.1 \%$ and $55.6 \%$, respectively. Similarly, more than half of the controls had null genotypes for GSTM1 and GSTT1, 56.5\% and $50.4 \%$, respectively. Overall, no significant association was found between GSTM1 or GSTT1 null genotypes and the risk of $A D$ in children. In contrast, the distribution of the GSTP1 Ile 105Val allele was significantly different between children with $A D$ and controls. Carriers of the GSTP1 Val105 allele (Ile/Val or Val/Val) were more frequent among children with $A D$ compared with controls $(37.9 \%$ and $27.3 \%$, respectively). Using logistic regression analyses with adjustments for gender and age, children with the GSTP1 Val105 allele had a 1.6-fold increased risk of developing AD compared to GSTP1 lle/lle homozygotes $(95 \% \mathrm{Cl} 1.03-2.56)$ (Table 2). However, this association was not statistically significant after Bonferroni correction for multiple testing. The distribution of GSTP1 Ile/lle, Ile/Val, and Val/Val genotypes in controls was $72.7 \%, 25 \%$, and $2.3 \%$, respectively. The frequency of the Val105 allele was $14.8 \%$.

We also investigated the risk of $A D$ associated with combinations of two GST genotypes. The combination of the GSTP1 Val105 allele and GSTT1 null geno- type increased the $A D$ risk by up to 2.3 -fold $195 \% \mathrm{Cl}$ 1.19-4.41) compared to GSTP /le/lle homozygotes and children with GSTT1 genotypes (Table 3). However, the significance of the association was lost after Bonferroni correction. The combination of the GSTP1 Val105 allele and the GSTM1 null also appeared to increase the risk of $A D(O R=1.73,95 \% \mathrm{Cl} 0.93-3.21)$, although this increase was not statistically significant $(p=0.09)$. There was no significant increase in AD risk with respect to GSTM1 and GSTT1 genotypes.

To investigate if the degree of oxidative stress was associated with AD, we compared blood concentrations of GSH, TAC, and MDA between children with $A D$ and controls (Figure 1). Mean serum TAC was significantly lower in children with $A D(1.70 \mathrm{mM}$ trolox eq.) compared with controls (1.43 $\mathrm{mM}$ trolox eq.) $(p<0.001)$. However, mean plasma concentrations of MDA were higher, although not significantly, in children with $A D$ compared with controls (686.9 nM vs. $593 \mathrm{nM}$, respectively, $\mathrm{p}=0.12$ ) (Figure 1).

To further explore the mechanisms that could explain the association of the GSTP1 polymorphism with increased risk of developing $A D$ we analyzed the above biomarkers with respect to the GSTP1 Ile105Val genotype. GSTP1 Ile/lle homozygotes had significantly higher concentrations of GSH compared with Val105 allele carriers $(10.8 \mu \mathrm{mol} / \mathrm{g} \mathrm{Hb}$ vs. $10.1 \mu \mathrm{mol} / \mathrm{g} \mathrm{Hb}$, respectively, $\mathrm{p}=0.03$ ) (Table 4). When we stratified the subjects into two groups (children with $A D$ and controls), the association of the GSTP1 genotype with erythrocyte GSH concentrations in each group was consistent with data derived

Table 2 Distribution of GST genotypes among patients with atopic dermatitis (AD) and controls.

\begin{tabular}{|c|c|c|c|c|}
\hline Genotype & AD patients & Controls & OR $(95 \% \mathrm{Cl})^{\mathrm{a}}$ & $\mathrm{p}$-Value \\
\hline \multicolumn{5}{|l|}{ GSTM1 } \\
\hline Present & $52(41.9)^{\mathrm{b}}$ & $113(43.5)$ & 1 ref. & \\
\hline Null & $72(58.1)$ & $147(56.5)$ & $1.042(0.674-1.610)$ & 0.85 \\
\hline \multicolumn{5}{|l|}{ GSTT1 } \\
\hline Present & $55(44.4)$ & $129(49.6)$ & 1 ref. & \\
\hline Null & $69(55.6)$ & $131(50.4)$ & $1.225(0.795-1.885)$ & 0.36 \\
\hline \multicolumn{5}{|l|}{ GSTP1 } \\
\hline$\| e / I l e$ & $77(62.1)$ & $189(72.7)$ & 1 ref. & \\
\hline Ile/Val or $\mathrm{Val} / \mathrm{Val}$ & $47(37.9)$ & $71(27.3)$ & $1.624(1.029-2.564)$ & 0.04 \\
\hline
\end{tabular}

${ }^{\mathrm{a}} \mathrm{OR}$ (odds ratio) and $95 \% \mathrm{Cl}$ were obtained from logistic regression after adjustment for gender and age; ${ }^{\mathrm{b}}$ values are numbers (\%). 
Table 3 Distribution of combined GST genotypes among patients with atopic dermatitis (AD) and controls.

\begin{tabular}{|c|c|c|c|c|}
\hline Genotype & AD patients & Controls & OR $(95 \% \mathrm{Cl})^{\mathrm{a}}$ & $\mathrm{p}$-Value \\
\hline \multicolumn{5}{|l|}{ GSTM1 and GSTT1 } \\
\hline Both present & $22(17.7)^{b}$ & $56(21.5)$ & 1 ref. & \\
\hline Either null & $63(50.8)$ & $130(50.0)$ & $1.254(0.702-2.238)$ & 0.44 \\
\hline Both null & $39(31.5)$ & $74(28.5)$ & $1.309(0.697-2.459)$ & 0.40 \\
\hline \multicolumn{5}{|l|}{ GSTM1 and GSTP1 } \\
\hline Present and Ile/lle & $35(28.2)$ & $82(31.5)$ & 1 ref. & \\
\hline Present and Ile/ Val or Val/Nal & $17(13.7)$ & $31(11.9)$ & $1.270(0.622-2.593)$ & 0.51 \\
\hline Null and Ile/lle & $42(33.9)$ & $107(41.2)$ & $0.894(0.523-1.529)$ & 0.68 \\
\hline Null and Ile/ Val or Val/Nal & $30(24.2)$ & $40(15.4)$ & $1.725(0.928-3.208)$ & 0.09 \\
\hline \multicolumn{5}{|l|}{ GSTT1 and GSTP1 } \\
\hline Present and I/e/lle & $35(28.2)$ & $87(33.5)$ & 1 ref. & \\
\hline Present and Ile/Val or Val/Nal & $20(16.1)$ & $42(16.1)$ & $1.175(0.605-2.283)$ & 0.63 \\
\hline Null and Ile/lle & $42(33.9)$ & $102(39.2)$ & $1.007(0.590-1.720)$ & 0.98 \\
\hline Null and Ile/Val or Val/Nal & $27(21.8)$ & $29(11.2)$ & $2.286(1.186-4.406)$ & 0.01 \\
\hline
\end{tabular}

${ }^{\mathrm{a}} \mathrm{OR}$ and $95 \% \mathrm{Cl}$ were obtained from logistic regression after adjustment for gender and age; ${ }^{\mathrm{b}}$ values are numbers $(\%)$.
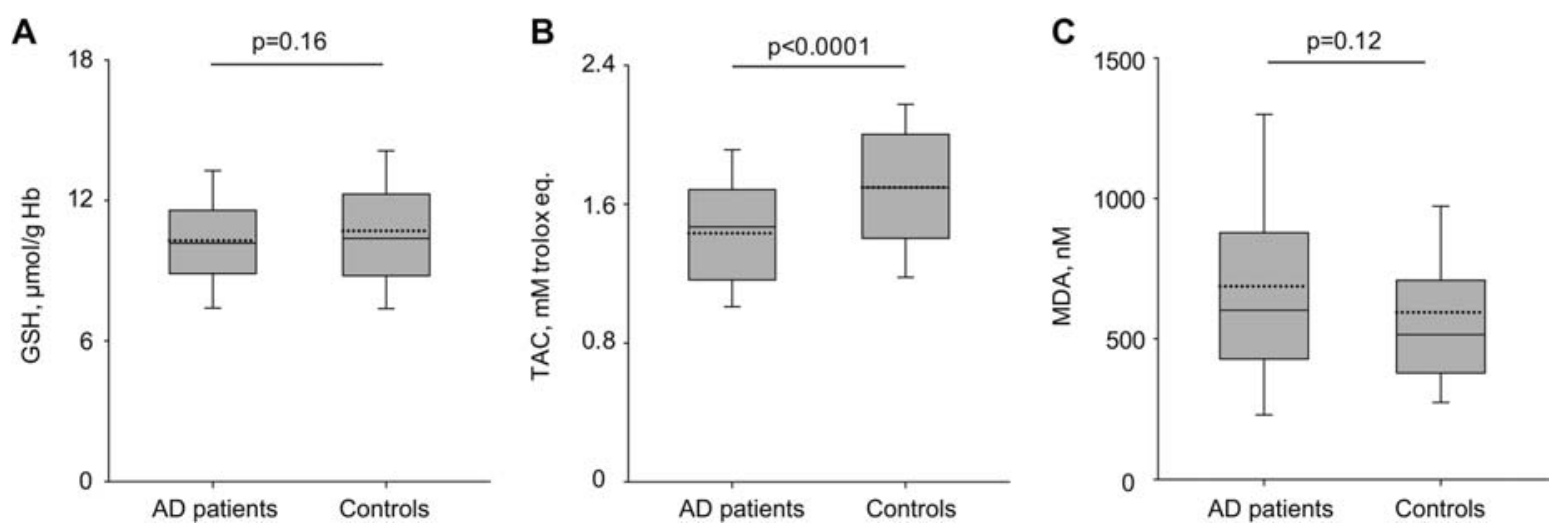

Figure 1 Blood GSH (A), TAC (B), and MDA (C) in patients with AD and controls.

Data are expressed as median and interquartile ranges. Dashed line (...) shows means. p-Values are obtained from Student's t-test. GSH, glutathione; TAC, total antioxidant capacity; MDA, malondialdehyde; AD, atopic dermatitis.

Table 4 Blood levels of glutathione (GSH), total antioxidant capacity (TAC), and malondialdehyde (MDA) with respect to GSTP1 genotype.

\begin{tabular}{|c|c|c|c|c|c|c|}
\hline & $\begin{array}{l}\mathrm{GSH}, \\
\mu \mathrm{mol} / \mathrm{g} \mathrm{Hb}\end{array}$ & $p-$ Value $^{a}$ & $\begin{array}{l}\text { TAC, mM } \\
\text { trolox eq. }\end{array}$ & $p$-Value & MDA, nM & $\mathrm{p}$-Value \\
\hline \multicolumn{7}{|l|}{ All subjects } \\
\hline GSTP1 Ile/lle & $10.8 \pm 0.18^{b}$ & \multirow{2}{*}{0.03} & $1.69 \pm 0.02$ & \multirow{2}{*}{0.14} & $611.1 \pm 32.2$ & \multirow{2}{*}{0.47} \\
\hline GSTP1 Ile/Val or $\mathrm{Val} / \mathrm{Val}$ & $10.1 \pm 0.23$ & & $1.62 \pm 0.04$ & & $655.6 \pm 53.9$ & \\
\hline \multicolumn{7}{|l|}{ AD patients } \\
\hline GSTP1 Ile/lle & $10.5 \pm 0.30$ & \multirow[b]{2}{*}{0.33} & $1.49 \pm 0.05$ & \multirow{3}{*}{0.66} & $689.2 \pm 64.2$ & \multirow[b]{2}{*}{0.95} \\
\hline GSTP1 Ile/Val or $\mathrm{Val} / \mathrm{Val}$ & $10.0 \pm 0.33$ & & $1.46 \pm 0.05$ & & $682.6 \pm 98.0$ & \\
\hline \multicolumn{6}{|l|}{ Controls } & \\
\hline GSTP1 Ile/lle & $10.9 \pm 0.23$ & \multirow[b]{2}{*}{0.12} & $1.75 \pm 0.03$ & \multirow{2}{*}{0.72} & $577.0 \pm 36.4$ & \multirow[b]{2}{*}{0.38} \\
\hline GSTP1 Ile/ $\mathrm{Val}$ or $\mathrm{Val} / \mathrm{Val}$ & $10.2 \pm 0.33$ & & $1.73 \pm 0.05$ & & $639.4 \pm 64.4$ & \\
\hline
\end{tabular}

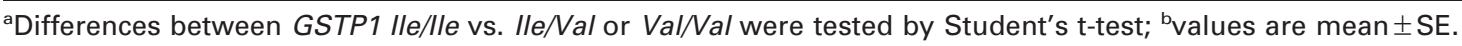

from all subjects, but this was not statistically significant (Table 4). No significant differences were found in TAC or MDA with respect to GSTP1 genotype in children with $A D$ or healthy controls.

\section{Discussion}

GST enzymes are critical for the detoxification of ROS and their products, which have been implicated in the pathology of inflammatory diseases such as AD. We reasoned that genetic polymorphisms of GST enzymes, which alter cellular protection against oxidative damage, may contribute to the risk of development of AD. We examined the association of GSTP1, GSTM1, and GSTT1 gene polymorphisms with the risk of $A D$ in preschool age children. The Val105 allele of GSTP1 was significantly associated with a higher risk of $A D$. In addition, children with a particular combination of variant genotypes (GSTP1 
Val105 and GSTT1 null) had an even greater risk (2.3fold increase) of $A D$, compared to children with GSTP1 Ile/lle and GSTT1 present genotypes.

GST gene polymorphisms have been associated with the risk of various skin diseases. For example, the GSTP1 Val105 allele has been shown to increase the incidence of arsenic-related skin lesions $(26,27)$. This is consistent with our observations that GSTP1 Val105 allele carriers had an increased risk of developing AD. However, many reports have shown that the Val105 allele is associated with a decreased risk of allergic asthma $(12,13)$, although some studies reported that the Val105 allele actually increased the risk of asthma $(14,16)$. The GSTP1 Ile 105Val polymorphism was not significantly associated with aspirin-intolerant asthma in Koreans (28). There are several possible explanations for the discrepancies between these studies and our findings. First, the pathogenesis of asthma and $A D$ may be quite different. Asthma involves changes in lung function while $A D$ is a type of skin disease. Thus, comparison of data from asthma patients with AD may not be appropriate. Second, the frequencies of the Val105 allele in Asians are much lower than those of other ethnicities, which may explain the conflicting findings. For example, the Val105 allele decreased the risk of asthma in Northern Europeans for which the Val allele frequency is $47.7 \%$ (12), whereas the Val105 allele increased the risk of asthma in the Japanese population for which the $\mathrm{Val}$ allele frequency is $13.4 \%$ (14). Studies in Taiwanese individuals ( $V a l$ allele frequency $=25.3 \%$ ) (15) have shown that the Ile105 homozygosity was related to an increased risk only in areas with high air pollution, and no association was found in areas with low air pollution. These data suggest that the role of GSTP Ile $105 \mathrm{Val}$ polymorphisms in the risk of $A D$ could differ depending on ethnicity. The frequency of the Val105 allele in our study was $14.8 \%$, which is very close to that of the Japanese population. Finally, other factors such as the subjects age and environmental factors may also cause differences.

Unlike the GSTP1 lle105Val polymorphism, neither GSTM1 nor GSTT1 present/null polymorphisms alone had a significant effect on risk of AD. In contrast, we found that carriers of two variant genotypes (GSTP1 Val105 and GSTT1 null) were at higher risk of AD than carriers of a single variant GSTP1 or GSTT1 genotype, or carriers of no variant genotypes. Also, the combined effect of the GSTP1 and GSTM1 variant genotypes on the risk of $A D$ tended to be higher than the effect of GSTP1 or GSTM1 variants alone. Similar to our findings, several studies have indicated that the influences of GST genotypes on disease risk become more significant with an increase in the number of GST variant alleles (29-31). This is likely due to GST enzymes having similar substrate specificities. While the absence or defect of a single GST enzyme has negligible effect on the risk of disease, possibly due to compensation by other GSTs, defects in multiple GST enzymes may contribute to significant alterations in cellular protection against oxidative stress and increase susceptibility to disease.

Earlier studies have reported that oxidative stress is associated with the development and severity of AD. Urine concentrations of 8-hydroxy-2'-deoxyguanosine (8-OHdG, a marker of oxidative DNA damage) are significantly higher in children with $A D$ compared with healthy controls (8). Also, urinary acrolein-lysine adducts (markers of lipid peroxidation) are significantly higher in children with AD (32). Our data showed that TAC was significantly decreased, but plasma MDA (products of lipid peroxidation) tended to be increased in children with $A D$ compared to healthy controls. This supports the association of oxidative stress and altered antioxidant status with development of AD. The relatively small difference in plasma MDA and erythrocyte GSH between the two groups may be due to the fact that most of the children with $A D$ that participated in our study had a mild case of the disease. Niwa et al. (33) have shown that the concentrations of carbonyl moieties (markers of oxidative protein damage) are increased in skin biopsies from patients with $A D$, and are directly correlated with disease severity.

We found that GSTP1 Val105 allele carriers had significantly lower GSH concentrations compared to GSTP1 Ile/lle homozygotes. Although the difference in GSH concentrations between genotypes is relatively small and may not be clinically significant, this observation suggests a potential mechanism for how the GSTP1 lle 105Val polymorphism increases the risk of AD. Since GSH is an important component that acts to scavenge ROS and regenerate other antioxidants, GSH depletion may represent increased oxidative stress in GSTP1 Val105 allele carriers. Similar to our findings, Ercan et al. (34) reported that asthma patients with homozygous GSTP1 Val105 genotypes have lower GSH concentrations compared to patients with other genotypes. The Ile to Val substitution at position 105 results in steric restriction of the putative binding site ( $\mathrm{H}$-site) due to shifts in the side chains of several amino acids. This steric hinderance may alter the substrate specificity and catalytic activity of GSTP1. In vitro studies have shown that the Val105 variant is more active with diol epoxides of polycyclic aromatic hydrocarbons (35), but less active than the Ile105 enzyme with various other substrates, including 1-chloro-2,4-dinitrobenzene (36). Further, the thermal stability of the Val105 enzyme is reported to be significantly lower than that of the lle105 enzyme (37). More importantly, erythrocytes from individuals with the Val105 allele displayed significantly decreased GST activity compared with that seen in I/e/lle homozygotes (38). Together, these characteristics may be responsible for the increased oxidative stress of GSTP1 Val105 carriers and for the increased susceptibility to AD.

It is interesting to note that serum TAC was much lower in children with AD compared with healthy controls. However, no significant differences were found with respect to GSTP1 genotype. This suggests that 
low TAC could be an independent risk factor for $A D$, in addition to GSTP1 genotype. Serum TAC measurements represent the combined activities of all antioxidants present in serum, including dietary antioxidant vitamins such as ascorbic acid, $\alpha$-tocopherol, and $\beta$-carotene (24). The imbalance of ROS production and antioxidants can lead to increased oxidative stress. Thus, it is possible that in addition to increased ROS production, low TAC in children with $A D$ may be due to low intake of dietary antioxidants, implicating dietary antioxidant intake with $A D$ risk. Several previous studies have reported the beneficial association of dietary antioxidant vitamins with the risk of atopic diseases (39-41). For example, a higher concentration of vitamin $\mathrm{C}$ in breast milk is associated with a reduced risk of $A D$ in infants $(\mathrm{OR}=0.30,95 \% \mathrm{Cl} 0.09-0.94)$ (42). Further studies to identify potential interactions between dietary antioxidant intake and GSTP1 genotype in the risk of $A D$ are needed.

In conclusion, our results suggest that the GSTP1 Val105 allele is an important determinant for susceptibility to $A D$ in preschool age children. These findings suggest a role for increased oxidative stress and altered antioxidant status in the pathogenesis of the disease. This study is limited by the small number of subjects and the associations of the GST polymorphisms with $A D$ risk become suggestive after Bonferroni correction. Further studies with larger sample sizes are needed to confirm and substantiate the present findings.

\section{Conflict of interest statement}

Authors report no conflict of interest.

\section{Acknowledgements}

The present study was supported by grant No. R01-2006-00010887-0 from the Basic Research Program of the Korea Science \& Engineering Foundation.

\section{References}

1. Levy RM, Gelfand JM, Yan AC. The epidemiology of atopic dermatitis. Clin Dermatol 2003;21:109-15.

2. Leung DY, Bieber T. Atopic dermatitis. Lancet 2003;361: 151-60.

3. Schultz Larsen F. Atopic dermatitis: a genetic-epidemiologic study in a population-based twin sample. J Am Acad Dermatol 1993;28:719-23.

4. Chien YH, Hwu WL, Chiang BL. The genetics of atopic dermatitis. Clin Rev Allerg Immu 2007;33:178-90.

5. Kapp A, Zeck-Kapp G, Czech W, Schopf E. The chemokine RANTES is more than a chemoattractant: characterization of its effect on human eosinophil oxidative metabolism and morphology in comparison with IL-5 and GM-CSF. J Invest Dermatol 1994;102:906-14.

6. Polla BS, Ezekowitz RA, Leung DY. Monocytes from patients with atopic dermatitis are primed for superoxide production. J Allergy Clin Immun 1992;89:545-51.
7. Portugal M, Barak V, Ginsburg I, Kohen R. Interplay among oxidants, antioxidants, and cytokines in skin disorders: present status and future considerations. Biomed Pharmacother 2007;61:412-22.

8. Omata N, Tsukahara H, Ito S, Ohshima Y, Yasutomi M, Yamada $A$, et al. Increased oxidative stress in childhood atopic dermatitis. Life Sci 2001;69:223-8.

9. Hayes JD, Strange RC. Potential contribution of the glutathione S-transferase supergene family to resistance to oxidative stress. Free Radical Res 1995;22:193-207.

10. Ali-Osman F, Akande O, Antoun G, Mao JX, Buolamwini $\mathrm{J}$. Molecular cloning, characterization, and expression in Escherichia coli of full-length cDNAs of three human glutathione S-transferase Pi gene variants. Evidence for differential catalytic activity of the encoded proteins. J Biol Chem 1997;272:10004-12.

11. Bolt HM, Thier R. Relevance of the deletion polymorphisms of the glutathione S-transferases GSTT1 and GSTM1 in pharmacology and toxicology. Curr Drug Metab 2006;7:613-28.

12. Fryer AA, Bianco A, Hepple M, Jones PW, Strange RC, Spiteri MA. Polymorphism at the glutathione S-transferase GSTP1 locus. A new marker for bronchial hyperresponsiveness and asthma. Am J Resp Crit Care 2000; 161:1437-42.

13. Hemmingsen A, Fryer AA, Hepple M, Strange RC, Spiteri MA. Simultaneous identification of GSTP1 Ile105 $\rightarrow$ Val105 and Ala114 $\rightarrow$ Val114 substitutions using an amplification refractory mutation system polymerase chain reaction assay: studies in patients with asthma. Respir Res 2001;2:255-60.

14. Kamada F, Mashimo Y, Inoue H, Shao C, Hirota T, Doi $\mathrm{S}$, et al. The GSTP1 gene is a susceptibility gene for childhood asthma and the GSTM1 gene is a modifier of the GSTP1 gene. Int Arch Allergy Imm 2007;144:275-86.

15. Lee $Y L$, Lin YC, Lee YC, Wang JY, Hsiue TR, Guo YL. Glutathione S-transferase $\mathrm{P} 1$ gene polymorphism and air pollution as interactive risk factors for childhood asthma. Clin Exp Allergy 2004;34:1707-13.

16. Tamer L, Calikoglu M, Ates NA, Yildirim H, Ercan B, Saritas $E$, et al. Glutathione-S-transferase gene polymorphisms (GSTT1, GSTM1, GSTP1) as increased risk factors for asthma. Respirology 2004;9:493-8.

17. Morinobu S, Morinobu A, Kanagawa S, Hayashi N, Nishimura K, Kumagai S. Glutathione S-transferase gene polymorphisms in Japanese patients with rheumatoid arthritis. Clin Exp Rheumatol 2006;24:268-73.

18. Nickel R, Haider A, Sengler C, Lau S, Niggemann B, Deichmann KA, et al. Association study of glutathione Stransferase P1 (GSTP1) with asthma and bronchial hyper-responsiveness in two German pediatric populations. Pediatr Allergy Immu 2005;16:539-41.

19. Safronova OG, Vavilin VA, Lyapunova AA, Makarova SI, Lyakhovich VV, Kaznacheeva LF, et al. Relationship between glutathione $\mathrm{S}$-transferase $\mathrm{P} 1$ polymorphism and bronchial asthma and atopic dermatitis. B Exp Biol Med + 2003;136:73-5.

20. Vavilin VA, Safronova OG, Lyapunova AA, Lyakhovich VV, Kaznacheeva LF, Manankin NA, et al. Interaction of GSTM1, GSTT1, and GSTP1 genotypes in determination of predisposition to atopic dermatitis. B Exp Biol Med+ 2003;136:388-91.

21. Oh JW, Pyun BY, Choung JT, Ahn KM, Kim CH, Song SW, et al. Epidemiological change of atopic dermatitis and food allergy in school-aged children in Korea between 1995 and 2000. J Korean Med Sci 2004;19: 716-23.

22. Harries LW, Stubbins MJ, Forman D, Howard GC, Wolf $\mathrm{CR}$. Identification of genetic polymorphisms at the glutathione S-transferase $\mathrm{Pi}$ locus and association with sus- 
ceptibility to bladder, testicular and prostate cancer. Carcinogenesis 1997;18:641-4.

23. Wilson MH, Grant PJ, Hardie LJ, Wild CP. Glutathione Stransferase $M 1$ null genotype is associated with a decreased risk of myocardial infarction. FASEB J 2000; 14:791-6.

24. Rice-Evans C, Miller NJ. Total antioxidant status in plasma and body fluids. Method Enzymol 1994;234:279-93.

25. Rahman I, Kode A, Biswas SK. Assay for quantitative determination of glutathione and glutathione disulfide levels using enzymatic recycling method. Nat Protoc 2006;1:3159-65.

26. Lin GF, Du H, Chen JG, Lu HC, Guo WC, Meng H, et al. Arsenic-related skin lesions and glutathione S-transferase P1 A1578G (Ile105Val) polymorphism in two ethnic clans exposed to indoor combustion of high arsenic coal in one village. Pharmacogenet Genomics 2006;16:86371.

27. McCarty KM, Ryan L, Houseman EA, Williams PL, Miller DP, Quamruzzaman $\mathrm{Q}$, et al. A case-control study of GST polymorphisms and arsenic related skin lesions. Environ Health 2007;6:5.

28. Oh JM, Kim SH, Suh $\mathrm{CH}, \mathrm{Nahm} \mathrm{DH}$, Park HS, Lee YM, et al. Lack of association of glutathione S-transferase P1 Ile105Val polymorphism with aspirin-intolerant asthma. Korean J Intern Med 2005;20:232-6.

29. Oniki K, Hori M, Takata K, Yokoyama T, Mihara S, Marubayashi $\mathrm{T}$, et al. Association between glutathione $\mathrm{S}$ transferase $\mathrm{A} 1, \mathrm{M} 1$ and $\mathrm{T} 1$ polymorphisms and hypertension. Pharmacogenet Genomics 2008;18:275-7.

30. Sorensen M, Raaschou-Nielsen O, Brasch-Andersen C, Tjonneland A, Overvad K, Autrup H. Interactions between GSTM1, GSTT1 and GSTP1 polymorphisms and smoking and intake of fruit and vegetables in relation to lung cancer. Lung Cancer 2007;55:137-44.

31. Hori M, Oniki K, Nakagawa T, Takata K, Mihara S, Marubayashi $\mathrm{T}$, et al. Association between combinations of glutathione-S-transferase M1, T1 and P1 genotypes and non-alcoholic fatty liver disease. Liver Int 2009;29:164-8.

32. Tsukahara H, Shibata R, Ohshima Y, Todoroki Y, Sato S, Ohta $\mathrm{N}$, et al. Oxidative stress and altered antioxidant defenses in children with acute exacerbation of atopic dermatitis. Life Sci 2003;72:2509-16.

33. Niwa Y, Sumi H, Kawahira K, Terashima T, Nakamura T, Akamatsu $\mathrm{H}$. Protein oxidative damage in the stratum corneum: evidence for a link between environmental oxidants and the changing prevalence and nature of atopic dermatitis in Japan. Br J Dermatol 2003;149:248-54.

34. Ercan $H$, Birben E, Dizdar EA, Keskin O, Karaaslan C, Soyer OU, et al. Oxidative stress and genetic and epidemiologic determinants of oxidant injury in childhood asthma. J Allergy Clin Immun 2006;118:1097-104.

35. Hu X, Herzog C, Zimniak P, Singh SV. Differential protection against benzo[a]pyrene-7,8-dihydrodiol-9,10epoxide-induced DNA damage in HepG2 cells stably transfected with allelic variants of pi class human glutathione S-transferase. Cancer Res 1999;59:2358-62.

36. Moyer AM, Salavaggione OE, Wu TY, Moon I, Eckloff BW, Hildebrandt MA, et al. Glutathione s-transferase p1: gene sequence variation and functional genomic studies. Cancer Res 2008;68:4791-801.

37. Johansson AS, Stenberg G, Widersten M, Mannervik B. Structure-activity relationships and thermal stability of human glutathione transferase P1-1 governed by the $\mathrm{H}$ site residue 105. J Mol Biol 1998;278:687-98.

38. Zhong SL, Zhou SF, Chen X, Chan SY, Chan E, Ng KY, et al. Relationship between genotype and enzyme activity of glutathione S-transferases M1 and P1 in Chinese. Eur J Pharm Sci 2006;28:77-85.

39. Devereux G, Seaton A. Diet as a risk factor for atopy and asthma. J Allergy Clin Immun 2005;115:1109-17.

40. Harik-Khan RI, Muller DC, Wise RA. Serum vitamin levels and the risk of asthma in children. Am $\mathrm{J}$ Epidemiol 2004;159:351-7.

41. Martindale S, McNeill G, Devereux G, Campbell D, Russell G, Seaton A. Antioxidant intake in pregnancy in relation to wheeze and eczema in the first two years of life. Am J Resp Crit Care 2005;171:121-8.

42. Hoppu U, Rinne M, Salo-Vaananen P, Lampi AM, Piironen $\mathrm{V}$, Isolauri $\mathrm{E}$. Vitamin $\mathrm{C}$ in breast milk may reduce the risk of atopy in the infant. Eur J Clin Nutr 2005;59: 123-8. 